\title{
The use of behavioural additionality evaluation in innovation policy making
}

\author{
Abdullah Gök* and Jakob Edler \\ Manchester Institute of Innovation Research, MBS, University of Manchester \\ *Corresponding author. Email: abdullah.gok@manchester.ac.uk
}

\begin{abstract}
The key object of innovation policy is to change behaviour of actors in order to improve innovation capabilities and outcomes. The overarching aim of this article is to improve our understanding of how this behavioural additionality (BA) can be better conceptualized and put into practice in evaluation and policy making. The article first outlines the theoretical framework of the concept of BA. On that basis it looks in detail at the way BA is currently operationalized in evaluation practice and how the concept is applied in the interaction between policy makers and evaluators. The article utilizes a statistical analysis of 171 innovation policy evaluations, a text analysis of selected BA evaluation reports, and finally a number of in-depth case studies of evaluations. Based on the conceptualization and the empirical findings, the article identifies three different uses of BA in innovation policy evaluations. The article further concludes that despite the widespread use of the concept of BA, an improved theoretical basis and serious methodological improvements are needed to realize the full potential of the concept for evaluation and policy practice.
\end{abstract}

Keywords: behavioural additionality; evaluation; innovation policy; policy-making; evaluation use.

\section{Introduction}

Innovation is the origination or adoption of a novel idea and its transfer into a practical application. Firms develop innovative products and services in order to offer an advantage to their customers compared with the established product or service. Firms, as well as public and third sector organizations, also constantly innovate in their internal processes and organizational set up. To innovate means to do something differently in order to be more efficient and effective in pursuing one's goals. To do things differently, individuals and organizations have to change behaviour. They have to learn, adopt knowledge, develop new skills, practices and routines, and apply all this in their respective contexts (OECD and EUROSTAT 2006).

Consequently, innovation policy is the set of public measures that try to enable and incentivise actors to innovate, i.e. to increase their capabilities and willingness to learn and change their behaviour. The basic intervention logic for innovation policy is thus not only market failure (under-investment in research to innovate) and system failure (e.g. lack of cooperation and networking), as the innovation policy literature has it, but also capability and adoption failure (e.g. support to enable change in behaviour) (Georghiou 1998a; Metcalfe and Georghiou 1998; Smith 2000; Bryant 2001; Hall 2002; Larosse 2004; Bach and Matt 2005; Schwerin and Werker 2006; Dodgson et al. 2010). Innovation policy is designed and implemented with a view to tackle all three failures. Almost all innovation policies, explicitly or implicitly, thus aim at a change of capabilities and behaviours to some degree, at individual or organizational level.

One major tool to support the design and implementation of innovation policy is evaluation. Evaluation of innovation policy (or its various earlier variants such as technology policy, R\&D policy etc.) traditionally looks at what impact policy has on the performance of the target group, both in terms of changes in input, changes in output, and changes in the way things are done. During the 1990s, the latter dimension, i.e. changes in the way things are done, has been conceptualized in the academic literature as well as in evaluation practice in order to better understand how innovation policy actually can change the way things are 
done - and how this can be done in a more persistent way, beyond the impulse of the initial intervention (Georghiou and Laredo 2006).

There have been many different studies within the technology or innovation policy and evaluation literature on the change in behaviour through government action. However, an explicit concept of behavioural additionality (BA) was first coined by Georghiou and his colleagues (Buisseret et al. 1995). In its most general understanding, BA can be defined as the persistent change in what the target group of the policy is doing and how they are doing it, whereby this change is attributable to the policy action. After its coinage in 1995, the term has gained considerable attention first in scholarly literature and subsequently in evaluation practice in the domain of innovation policy. A broad OECD project in which a number of Member States conducted pilot studies to evaluate BA in their programmes marked the growing importance of the concept (OECD 2006).

In spite of the increasing uptake of the concept both in innovation policy evaluation and - to a lesser extent-in innovation policy design, $\mathrm{BA}$ is not yet fully matured. The definition and theorization of the concept still needs further work (Gok 2010), and the literature presents substantially different and sometimes conflicting perspectives of the concept, which results in further difficulties in its evaluation. As a consequence, the understanding of policy makers and evaluators alike as to what BA is and how it can be measured is diffuse. This means that there is a real risk that the most important dimension of innovation policy, change of behaviour of actors as a condition for innovation to happen, is not fully understood in policy practice. This also implies that the concept of BA is wrongly applied, under-evaluated or mis-used, which can ultimately contribute to under investment in innovation through under-appreciation (Aho et al. 2006; Georghiou 2007).

The overarching aim of this article is to contribute to a better understanding of how the main target variable of innovation policy - change in behaviour - can be better conceptualized and put into practice in evaluation and policy making. By doing so, we hope to make the concept of BA better understood and subsequently contribute to improving academic knowledge as well as concrete design and impact of innovation policy.

In order to achieve this aim, the article examines different conceptualizations of $\mathrm{BA}$ in the academic literature evaluation practice and subsequently analyses the use of the BA concept in innovation policy. Here, we focus on the use of the BA concept in evaluations, which are the major means for innovation policy makers to assess and redesign their policy measures. The article looks in detail at the way $\mathrm{BA}$ is conceptualized and operationalized in evaluation reports and how the concept is discussed and applied in the interaction between policy makers and evaluators. The study is based on a large-scale, systematic analysis of evaluation reports of innovation policy across Europe (Edler et al. 2012) and a set of in-depth case studies.

The article will start by outlining the origin of the concept in innovation policy and the various academic concepts of BA (Section 2). Section 3 presents the empirical analysis. After outlining the methodology applied (Section 3.1), this section portrays the variety of understandings of the concept in evaluation practice based on a detailed text analysis of 33 evaluation reports (Section 3.2). It then analyses the main characteristics of evaluations that cover BA based on a broad statistical analysis of 171 evaluation reports (Section 3.3). A final empirical section summarizes and discusses five case studies of the application of the BA concept in selected policy measures (Section 3.4). Section 4 discusses and interprets the various findings, while Section 5 outlines implications for further research and for policy making.

\section{The concept of BA in the academic literature}

Additionality is a key concept of innovation policy evaluation and refers to the question what difference a policy makes. The concepts of input additionality (i.e. additional inputs that would not have been created without a government intervention) and output additionality (i.e. outputs exclusively attributable to government intervention) are widely considered as the hallmark of the neoclassical policy rationale, which ultimately seeks to remedy market failures. If a government action designed to address market failures does not create more inputs and/or outputs than would have been created without it, then it is considered to be unsuccessful. The concept for BA goes beyond the market failure rationale. It is based on the evolutionary and structuralist view which urges policy action to increase cognitive capacities of agents in order to overcome a broad range of others failures such as system and knowledge processing failures. Thus, a policy is only successful if it increases the capacities of agents that are crucial for innovation activity and performance (cognitive, networking, etc.) and by doing so leads to persistent effects. Bach and Matt $(2002,2005)$ call this 'cognitive capacity additionality', while Georghiou and his colleagues (2004, 2007; Georghiou and Clarysse 2006) refer to it as 'behavioural additionality' (Lipsey and Carlaw 1998a, b, 2002; Bach and Matt 2002, 2005; Lipsey 2002; Lipsey et al. 2005).

Although the concept of BA has gathered considerable attention from a range of scholars, there is still no consensus as to what it means. Similarly, the concept still lacks a comprehensive theoretical basis and a sound, accepted operationalization. Gok $(2010,2011)$ classifies these definitions into a set of four categories (see also Table 1.)(A) BA as an extension of input additionality:

There are a number of papers that understand BA as a very simple concept that complements the excessively 
Table 1. Comparison of different definitions of BA

\begin{tabular}{|c|c|c|c|c|}
\hline & Category A & Category B & Category $\mathrm{C}$ & Category D \\
\hline Definition & $\begin{array}{l}\text { An extension of input } \\
\text { additionality covering scale, } \\
\text { scope, and acceleration } \\
\text { additionality and like }\end{array}$ & $\begin{array}{l}\text { The one off change in the be- } \\
\text { haviour related to R\&D } \\
\text { and innovation activities }\end{array}$ & $\begin{array}{l}\text { The change in the persistent } \\
\text { behaviour related to } R \& D \\
\text { and innovation activities }\end{array}$ & $\begin{array}{l}\text { The change in of the general } \\
\text { conduct of the firm } \\
\text { Substantial reference to } \\
\text { building blocks of } \\
\text { behaviour }\end{array}$ \\
\hline Coverage & Only R\&D and innovation & Only R\&D and innovation & Only R\&D and innovation & Beyond $\mathrm{R} \& \mathrm{D}$ and innovation \\
\hline Persistence & One-off, no persistence & $\begin{array}{l}\text { One-off, no persistence or } \\
\text { Rather mid-term than } \\
\text { long-term and rather less } \\
\text { persistent }\end{array}$ & $\begin{array}{l}\text { Persistent or Rather long-term } \\
\text { than short-term and rather } \\
\text { more persistent }\end{array}$ & Persistent \\
\hline
\end{tabular}

linear and strict nature of input additionality. For instance, Luukkonen (2000: 713) argues that 'input additionality and BA are usually merged together in a question that lists different degrees of additionality, whether the R\&D would not have been carried out at all without public support, or alternatively whether the public funding changed the scale and scope of the R\&D or R\&D would have been done differently'. Similarly, Hsu and his colleagues (Hsu and Hsueh 2009; Hsu et al. 2009) use the same definition in their closely related empirical articles.

Some other scholars accept that there might be further effects, although they either put the emphasis on the extensions of input additionality or they find only this definition workable (evaluable). One example here is Falk (2007) who defines BA as a broad category that includes scope and acceleration additionality (i.e. if the measure encourages the firms to conduct their projects in a bigger scope and faster than it would have been) as well as cognitive capacity additionality (i.e. if the cognitive capacity of agents are increased) and uses only the first two (scope and acceleration) in her empirical investigation. Another example is Malik et al. (2006: 206) who accept that BA is a multi-layered concept; all the same, they use and prefer the reduced definition. Finally, Georghiou (2002a: 59) defines BA as the superset of scale, scope, and acceleration additionality, while accepting that there might be more permanent effects within the umbrella of BA.

However, this type of $\mathrm{BA}$ is not really concerned with the persistence of the changes induced by the measure, and thus evaluations capture behavioural changes at only one point in time during the project. There is no particular emphasis on spill-over and endurance beyond the support period. Further, in this category, BA is perceived as confined to $R \& D$ and innovation activities of the firm.(B) BA as a one-off change in the behaviour related to $\mathrm{R} \& \mathrm{D}$ and innovation activities:

The second group of articles that define BA see the concept as capturing the change in behaviour of the agents. This change, contrary to Category A, is beyond an extension of input and output additionality. It not only includes scale, scope, and acceleration additionality for the concept of behavioural change, but also the way the project is undertaken.

The original definition of the BA concept is the prime example for this approach. Buisseret et al. (1995: 590) coined BA as 'the change in a company's way of undertaking R\&D which can be attributed to policy actions'. Later, Georghiou (2002b: 59) has elaborated on their definition by arguing that when defining BA, what they were inspired by was not the change in the 'stop-go decision by the firm in respect of the project but [...] rather the way in which the project was carried out'. Similarly, Georghiou (2004: 7) defines it as 'the difference in firm behaviour resulting from the intervention'. Clarysse et al. (2006) and Steurs et al. (2006: 6) endorse this and reinforce their view through the black-box analogy, whereby BA is what is inside the black-box of the firm, beyond input and output additionality. Finally, Hall and Maffioli (2008: 173) use this definition in their empirical investigation.

Similar to the definition Category A, the studies in Category B do not particularly stress the issue of persistency. They do not analyse if the change in behaviour is sustained beyond the project or its immediate vicinity. Clarysse et al. (2006) and Steurs et al. (2006: 6) hint at the persistence but, as will be discussed later on, their temporal understanding is still more short-term like than the definition Categories $\mathrm{C}$ and $\mathrm{D}$ below. In a similar vein, Georghiou (1998b: 39) and Davenport et al. (1998: 56) accept that BA is 'the most durable' among the three types of additionality, but fall short of analysing persistence systematically compared with the next two categories. Furthermore, this category is also confined to the behaviour related to $\mathrm{R} \& \mathrm{D}$ and innovation activities.

(C) BA as the change in the persistent behaviour related to $R \& D$ and innovation activities:

The third category of definitions of the concept of BA is very similar to the second one, with the main difference that now we have a more explicit and systematic capture of 
persistence. Aslesen et al. (2001: 5-6) define it as the 'permanent change', Licht (2003) as the change 'permanent in character', and OECD (2006: 187-189) as the 'more sustained effects'. Fier et al. (2006: 127) prefer to use 'long-term behaviour'. Busom and Fernandez-Ribas (2008) define it as the change in the propensity to exhibit a particular behaviour. In all these definitions and related evaluations, persistence is the key point; the policy induced effects endure beyond the support period.(D) BA as the persistent change in the general conduct of the firm:

The first feature in this category is that the change is not necessarily confined to $R \& D$ and innovation-related activities, but BA is defined as the induced change in the general conduct of the firm. Secondly, BA is defined in its widest temporal scope - it endures long after the support. Most importantly, the definitions of BA include more structural changes as they refer to the change in the individual building blocks of behaviour. The most explicit attempt to do this is by Georghiou and Clarysse (2006: 12-13) who employed the resource-based view of the firm and implied that BA refers to changes in the dynamic capabilities. Another attempt is by Bach and Matt (2005: 37) who defined a new category of cognitive capacity additionality. This extension, however, is meanwhile integrated into a broader concept of BA. As a matter of fact, Hyvarinen and Rautiainen (2007: 206) later adopted this approach by defining BA as how public $\mathrm{R} \& \mathrm{D}$ funding affects the firm's behaviour, cognitive capacity and learning, whereby they extended those effects beyond the R\&D and innovation activities of the firms. Similarly, some other scholars define BA as the change in organizational routines more generally (Georghiou and Keenan 2006; Georghiou 2007), but do not articulate their definitions. Finally, Clarysse and his colleagues (2009) utilize the concept of learning to define BA. However, they do not extend this broader concept into their empirical analysis where they stick to traditional indicators.

A more recent, and more holistic, approach to conceptualize BA (Gok 2010, 2011) argues that all these four broad categories of definitions of the concept of BA summarized in Table 1 share two common problems. First, the concept lacks a proper unit of analysis. BA studies and the literature in general criticize the inputoutput approach by claiming that it treats the firm as a black-box where certain measureable inputs create some outputs, neglecting the process within which this happens. However, the very same approach is mostly repeated in the current conception of BA because the literature successfully opens the black-box of the firm and discovers smaller black-boxes of behaviour. Consequently, these smaller boxes of behaviour are analysed in terms of their inputs and outputs, but not opened and properly analysed within. For instance, collaboration behaviour is evaluated in terms of the money spent on collaboration (i.e. input to collaboration behaviour) or the amount of collaboration (i.e. the consequences of collaboration behaviour) but not the building blocks of collaboration. Therefore, as 'behaviour' per se is not a unit of analysis, this approach suggests utilizing the concept of 'organizational routines' to study the change in the firm behaviour.

Secondly, BA needs a better framework of analysis. As opposed to input and output additionality which are seen as main elements of the neoclassical innovation policy rationale, BA is arguably the hallmark of the evolutionary/ structuralist perspective of innovation policy. If BA is to capture the logic and rationale of the evolutionary innovation paradigm, then it has to embrace a dynamic framework of analysis that corresponds with the evolutionary logic. In contrast, the various current measurement approaches of BA summarized above employ a comparative static framework of analysis in which input/output of behaviour (i.e. level of cooperation) prior to policy support is compared with the input/output of that behaviour once the firm is supported, by holding all other variables constant. Due to this ceteris paribus assumption, the change (i.e. the observed difference between these two static points) is then attributed to the government intervention and, hence, BA is estimated. This view not only limits the full potential of the concept but also hinders its compatibility within evolutionary thinking as the focus of the evolutionary/structuralist view to innovation policy making is not the end-result of the change but the actual process of change.

To overcome those two fundamental problems, (Gok 2010,2011 ) suggests a new understanding of BA based on two pillars. First, the evolution of organizational routines by government action must be conceptualized, operationalized, and analysed at three levels. The micro level refers to the evolution of particular organizational routines in particular firms by government action, the meso level refers to the evolution of particular organizational routines within a population of firms, and finally, the macro level refers to the evolution of social technologies (widely practiced and institutionalized organizational routines as defined by Nelson $(1991,2005,2009))$ within the economy. Secondly, a thorough analysis of BA needs to take into account the entire process and its dynamics by capturing the origination, adaption, and retention phases of evolutionary change in organizational routines.

These two pillars imply that a methodological clarification with regard to the epistemological stance of evaluations is necessary. The current practice of evaluation of BA employs sustaining causation which tries to explain how certain issues affect the equilibrium. The current corresponding counterfactual approach in evaluation is the parallel worlds view in which two stationary worlds are compared and the difference is attributed to BA by employing some experimental or quasi-experimental techniques. However, if $\mathrm{BA}$ is to be understood in an evolutionary framework as a more fundamental change 
in the organizational routines of firms, the corresponding mode should be originating causation which focuses on processes and developments, on becoming rather than being. This approach to $\mathrm{BA}$ requires a branching view which acknowledges that history is like a tree where each decision represents a separate branch. Therefore, counterfactual analysis is returning to a point where another branch is chosen. In order to understand what would have happened had there been no government intervention; one needs to trace every critical branching point after the public intervention up to the present (Gok 2011).

The next section will now turn to the actual use of the BA concept in concrete evaluations of policy measures in innovation policy.

\section{The understanding and use of BA in innovation policy making and evaluation}

\subsection{Data basis and methodology}

The empirical analysis presented in this article rests on three pillars: a statistical analysis, a text analysis of evaluation reports, and a set of case studies of evaluations. The original data for the statistical analysis is drawn from the INNO-Appraisal database which contains evaluation reports of a whole range of different innovation policy measures of EU25 countries that are covered in the European INNO-Policy Trendchart Database. The period covered is 2002 and 2007. The INNO-Appraisal database ${ }^{1}$ includes full characterizations of each evaluation including their purpose, timing, methods, impacts cover, quality, usefulness, consequences, dissemination, etc. The evaluation reports were characterized by a study team (for more detail see Edler et al. 2010). For some of the characterization issues (e.g. the usefulness of the evaluation) judgements of policy makers were captured through interviews. The overall number of characterization of evaluation reports is 216,171 of which include policy maker verification and judgement. Those two samples are used for the statistical analysis, depending on which variables are analysed.

For the text analysis we selected 33 evaluation reports that employed the concept of BA and that did so within evaluations that the project team had assessed as being of sufficient quality in terms of methods employed and data used. We also limited the selection to reports in the sample that were in English or German as the nuanced understanding of the text is crucial for the text analysis. The number 33 is sufficient for an explorative - rather than a representative - analysis of different BA understandings.

The selection of the in-depth cases built upon the text analysis of our 33 reports. The basic idea of these cases is to learn from good but varied applications. The first selection filter was: did the concept play a prominent role in the evaluation, implicitly (without naming it BA) or explicitly. The second criterion was: was the application of the concept thorough and promising to yield some meaningful insights? A third filter then was to make sure different variants of the concept were included, ranging from a simple understanding of BA as an increase in collaboration (which then, within this limitation was conducted carefully and in a sensible way), to complex differentiations of various building blocks of behaviour. And finally, the selection made sure that different kinds of policy measures were covered. The exploratory case analysis builds on a thorough investigation of the evaluation reports and the logic of the underlying policy measure, an analysis of the respective template that was filled in by policy makers, and subsequent semi-structured telephone interviews with the lead evaluators and - in most cases - the responsible policy maker.

\subsection{The different understandings of BA in evaluation practice}

In Section 2, we have outlined the different and sometimes conflicting understandings of BA in the scholarly literature. Against this background, our first empirical question is: how is BA conceptualized and defined in actual evaluation reports? To answer this question allows us to see if and how BA is understood in an applied real-life context. This can serve as a starting point to improve the application of the concept, and to arrive at a generally shared understanding that is rooted in academic literature.

The text analysis of the 33 reports covering BA investigated the following important dimensions that were featured in the analysis of scholarly literature discussed in the previous section:

- Was BA explicitly mentioned or used implicitly?

- What was the definition of BA?

- Did the implicit or explicit definition of BA include the elements of persistency (as persistency is at the core of $\mathrm{BA}$ as a consequence of learning and change processes)?

- Was the implicit or explicit definition of BA confined to R\&D behaviour only or to collaboration behaviour only?

- Were there are any references to the individual building blocks of behaviour (or was the concept not differentiated into such building blocks)?

To start with, not all of those reports explicitly used the term BA; some reports applied the idea of the concept without referring to it explicitly. This is in a way a first finding: it is often intuitively obvious to analyse change in behaviour, but this is often done without an explicit conceptual basis.

The further results of the analysis are summarized in Table 2. It reveals that the typology of the literature is replicated in evaluation practice, with a few minor differences. First of all, the two distinct categories of approaches to BA, i.e. 'the extension for input and output 
Table 2. Classification of definitions of BA in as applied in practice

\begin{tabular}{|c|c|c|c|c|c|}
\hline & Category $\mathrm{A}+\mathrm{B}$ & Category $\mathrm{C} 1$ & Category C2 & Category D & Other \\
\hline Definition & $\begin{array}{l}\text { The non-persistent exten- } \\
\text { sion of input } \\
\text { additionality or the } \\
\text { change in the } \\
\text { non-persistent behaviour }\end{array}$ & $\begin{array}{l}\text { Change in the persistent } \\
\text { behaviour }\end{array}$ & $\begin{array}{l}\text { Change in the persistent } \\
\text { behaviour with minor } \\
\text { references to building } \\
\text { blocks }\end{array}$ & $\begin{array}{l}\text { Change in the general } \\
\text { conduct of the firm, ref- } \\
\text { erence to building } \\
\text { blocks of behaviour }\end{array}$ & $\begin{array}{l}\text { Inconsistent or } \\
\text { not possible } \\
\text { to analyse }\end{array}$ \\
\hline Coverage & Only R\&D and innovation & Only R\&D and innovation & Only R\&D and innovation & $\begin{array}{l}\text { (Some of them) Beyond } \\
\text { R\&D and innovation }\end{array}$ & \\
\hline Observations & $\begin{array}{l}\text { - } 30 \% \text { of the all } \\
\text { evaluations } \\
\text { - Around one-third of } \\
\text { this category looks at } \\
\text { only collaboration } \\
\text { - BA mostly implicit }\end{array}$ & $\begin{array}{l}\text { - } 15 \% \text { of the all } \\
\text { evaluations } \\
\text { - Around half of this } \\
\text { category looks at only } \\
\text { collaboration } \\
\text { - BA mostly implicit }\end{array}$ & $\begin{array}{l}\text { - } 20 \% \text { of the all } \\
\text { evaluations } \\
\text { - Almost all evaluations } \\
\text { in this category looks } \\
\text { at only collaboration } \\
\text { - BA mostly implicit }\end{array}$ & $\begin{array}{l}\text { - } 15 \% \text { of the all } \\
\text { evaluations } \\
\text { Almost all evaluations } \\
\text { in this category looks } \\
\text { at collaboration as well } \\
\text { as other issues } \\
\text { BA is more explicit } \\
\text { than other categories }\end{array}$ & $\begin{array}{c}20 \% \text { of the all } \\
\text { evaluations }\end{array}$ \\
\hline
\end{tabular}

additionality' (Category A) and 'the change in the non-persistent behaviour related to R\&D and innovation activities' (Category B) form a single category in practice (Category $\mathrm{A}+\mathrm{B}$ ) as it was not possible to distinguish Category A from Category B in most of the cases. This means that there is one category of understanding that does not differentiate and sees BA as a residual category, as all kinds of changes not attributed to input or output additionality are labelled as BA, with no linkages to persistency of that change. Evaluations in this group (Category A $+\mathrm{B}$ ) form around one-third of the $33 \mathrm{BA}$ evaluations analysed. In this category, BA is most often used implicitly, without mentioning the term. Almost one-third of the evaluations in this category focus exclusively on the issue of collaboration.

In contrast, Category $\mathrm{C}$ as defined on the basis of the literature ('the change in the persistent behaviour related to R\&D and innovation activities') is slightly more differentiated in practice and thus can be split into two categories, those that look at BA as one distinct phenomenon (Category $\mathrm{C} 1$ ), and those that differentiate it into various building blocks (Category $\mathrm{C} 2$ ). This means that there are evaluations that look at persistent change in $\mathrm{R} \& \mathrm{D}$ and innovation-related behaviour, but do not differentiate, do not dig deeper as to what the different elements are that characterize that change. Furthermore, there are those that do the latter, but still do not enlarge the concept to the conduct of the firm more broadly (which would be Category D). The evaluations we find in Category D define $\mathrm{BA}$ as change in the general conduct of the firm with strong references to building blocks of behaviour.

The analysis showed that those four categories are more or less evenly distributed among the 33 evaluations. There is, in other words, no dominant understanding of BA. While some evaluators define it extremely narrow or not at all, others have a differentiated concept that defines and operationalizes building blocks and looks beyond R\&D and innovation activities. There is a clear link between the scope of the behaviour they investigate and the definition category. For instance, while Category A + B evaluations are mostly limited to collaboration behaviour, Category D evaluations have a much wider scope in terms of the type of behaviour they evaluate.

\subsection{The broader practice of using BA in evaluations-a statistical analysis}

Against the background of a fuzzy understanding of the concept of BA in evaluation practice, we now turn to the key question how BA is actually taken up and analysed in evaluation studies. To do so, we analyse the INNO-Appraisal data statistically and show if and how evaluations differ that apply the concept of BA from those that do not. For the first time, this allows to get a systematic picture of the nature of BA in practice.

The data analysis shows that BA is a well-established concept in evaluations: $50 \%$ of all the 216 reports in the database employ it, explicitly or implicitly. The concept is more often used for policy measures that foster networking and technology transfer, which is consistent with the need for learning, networking, and cooperation in those programmes. Figure 1. shows the relationship between the evaluations covering the three types of additionality and also the remaining evaluations that do not cover any type of additionality. Two-thirds of the innovation policy measure evaluations in the database cover at least one 




All Evaluations

$100 \%$

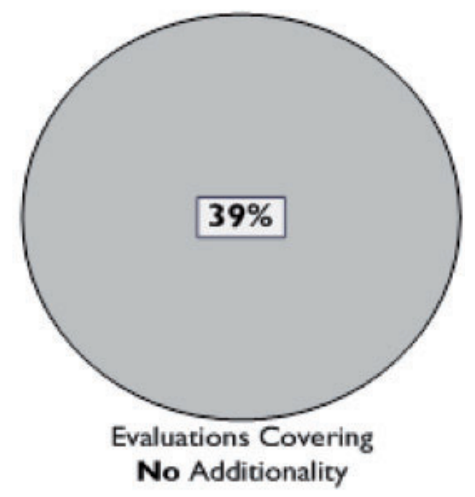

Figure 1. Euler diagram of the coverage of types of additionality in combination.

type of additionality, and one-third of evaluations cover all three types of additionality. Those covering BA exclusively, without any other form of additionality, constitute only one-fifth of all BA evaluations. This suggests that the three types of additionality are used extensively in evaluations and they are predominantly used together.

BA is also closely linked with the other topics concerning projects more than the programme, such as 'quality of outputs' and 'project implementation efficiency'. Evaluations that cover BA are also less likely to look at the social and environmental impact, but much more at the scientific and technological impact than the whole sample, while there are no significant differences for economic impact. All this is consistent with our conceptual expectations: BA is especially linked with the micro level, the firm or even project level, and the way a project is conducted or actions and routines are changed; it thus looks at the immediate difference this makes for the output (quality) rather than the wider impact.

While there is no difference between evaluations that are sponsored by the programme owners themselves or by other bodies, we observe that the concept is slightly less often applied in evaluations that are done internally and not by external evaluators. The application needs specific expertise and in-depth qualitative approaches, which seem to be best conducted by external evaluators. Interestingly, however, this does not imply that evaluators are keener to apply it than policy makers: the concept is more often applied in those evaluations that specify the methodology in the terms of reference and thus express a clear demand for BA approaches. This will be further discussed in the next section, as our in-depth case studies indeed confirm that both evaluators and policy makers can be the source for the application of the concept, it is not entirely evaluator driven (see Section 3.4).
In terms of data collection and methods of analysis, BA evaluations are not very different from other evaluations; therefore, they are not method biased. However, there are a number of minor differences worth noting. For instance, the share of BA evaluations that apply qualitative methods is by and large slightly higher than the share in the overall population of reports. Interestingly, however, BA evaluations also use surveys slightly more often. Those surveys very often limit themselves to the collaboration aspect of $\mathrm{BA}$, operationalizing the concept as change in cooperation behaviour. Existing data and monitoring data, in contrast, is not more often used in those evaluations. It appears that by and large existing monitoring data is not fit for purpose when it comes to understand and assess change in behaviour.

The idea of BA is that it should support the learning process of programme managers as well as the target group itself, and thus the concept is associated with a focus on interaction and learning and the need to re-adjust programme and implementation. Thus, we would expect that the BA concept is more often used in evaluations that accompany a policy measure. However, our analysis shows that the concept is not much more common in accompanying evaluations than other forms of additionality. Further, while the concept is also used in evaluations that are predominantly formative in nature, the difference is not as strong as one might think. BA, in other words, is also an essential part of summative evaluations that assess the performance (see Edler et al. 2012 for a broader discussion).

This is consistent with our last finding: compared with evaluations that do not look at BA, BA evaluations are more often discussed more broadly across and beyond government, and they are more often targeted towards the general public and towards users. However, when 
policy makers were asked about usefulness of recommendations in the reports, evaluations applying BA are not perceived to be significantly more useful for changes in policies than other evaluations.

\subsection{The challenges of using BA: learning from cases}

The previous sections have shown that the application of $\mathrm{BA}$ is a common practice in innovation policy evaluations, albeit poorly defined and under-exploited. In a last empirical step we elaborate on the opportunities and challenges of applying the BA concept in evaluations. Five in-depth evaluation case studies have been conducted which all cover programmes that seek to change behaviour. The selection of cases covers different forms of policy measures and different applications and conceptualizations of the BA concept for the evaluation. The following table summarizes the nature of the case studies along the key analytical dimensions for the conceptualization, use, and benefit of BA: the intentions of the underlying policy measure, the intended change on behaviour, the purpose of the evaluation, the key feature of the evaluation in relation to $\mathrm{BA}$, the operationalization of $\mathrm{BA}$, the interaction of evaluator and policy makers, the main methods, key challenges, limits, and the perceived benefits of this particular evaluation (see Table 3.).

To observe the benefits and challenges for the evaluation of behavioural change, we can read the table horizontally rather than analysing case by case. To begin with, there are very different ways in which behaviour is tackled in policy measures. The targeted behavioural change is often implicit or not pre-defined at all (Case 5), it can be one-dimensional (e.g. targeting cooperation capabilities of one type of actor, Case 1), or very broad and ambitious, extending to different types of actors, to different kind of action parameters and attitudes in different innovation stages and so on (Cases 2, 3, and 4). The latter asks for a much more elaborate and differentiated conceptualization of the BA concept. It also poses more challenges for measurement and for the link to the final impact of the measure. It is a common shortcoming of most of our cases that they limit themselves to a simplistic definition of BA as cooperation capabilities, even if the policy measure suggests otherwise (Cases 1 and 4).

Second, partly in consequence of this first observation, we see very different forms and processes to operationalize BA. Some BA evaluations try to break down perceived change in different components of actions and attitudes (as a basis for future action) measured at different points in time (e.g. cases 1-3). The cases also show that it is possible to conceptually link the change of parameters with change in the actual impact dimension (e.g. more innovation, Case 2). Ideally, this is done early in the process when designing the measure. The conceptual link between action and final intended impact needs constant check and triangulation.
A third observation is that the BA is not a core evaluation concept as yet and thus BA application necessitates clear communication between policy makers and evaluators about definitions, expectations, and limits as regards the concept. Although BA as a concept is contested, it is often not clarified at the outset of a programme or even at the beginning of the evaluation, but included only during the evaluation process. In two cases evaluators (Case 1) and programme managers (Case 5) have realized during the evaluation process that they need to measure change in behaviour in order to show the impact of the programme in the short and mid-term and to understand the ways in which further impact occurs. In both cases BA measurement had been contested, with policy makers either neglecting its importance and for a long time insisting on final output measurement only (Case 1) or using it entirely for legitimation purposes without taking advantage of the learning benefits BA concepts offer (Case 5). Interestingly, in one case the evaluator was not flexible enough to adjust to BA once the programme managers had realized its importance during the process (Case 4). All this points to the need of clear and early communication about the position and operationalization of BA between evaluator and programme management. This is crucial not only for a reliable and valid measurement of impact, but it is also essential for the learning process of policy makers about BA and programme impact logics. Especially Case 1 is a key example for policy makers' learning, albeit within limitations, while Case 5 shows how a sophisticated evaluation failed to trigger learning because of a lack of embedding evaluation into the programme management agency.

Fourth, there is a gulf between basic methods that are already being used broadly, and the necessary sophisticated methods for the purpose of BA evaluations. As we have already seen in the statistical analysis, most cases that apply some form of BA use very similar methods: (limited) monitoring data analysis, surveys, and interviews. This is seen by most actors as sufficient, and thus more sophisticated methods are rarely applied. In Case 1, the evaluator was clearly aware of the need for a mix of sociological, psychological, and organizational research approaches and related ethnographic methods to be applied over a broader period of time in order to fully capture the nature of change and how it was triggered by policy. Only with those approaches would evaluators be able to capture organizational routines and their change over time and would be able to attribute those changes to policy interventions as well as understanding the processes of learning of individuals and across organizational units. There seem to be two more general limitations here. One is that even if evaluators are aware of what an appropriate method and skill mix to fully capture behavioural change would look like, in the context of concrete policy relevant evaluations, this breadth and longitudinal approach is not realistic. Another limitation is that multiple control group 
Table 3. Overview of case studies on use of BA

\begin{tabular}{|c|c|c|c|c|c|}
\hline & Case 1 & Case 2 & Case 3 & Case 4 & Case 5 \\
\hline Policy measure & $\begin{array}{l}\text { Support for cooperation of } \\
\text { SME with firms and } \\
\text { PROs, broadening } \\
\text { networks, leading to } \\
\text { products, and market } \\
\text { introduction }\end{array}$ & $\begin{array}{l}\text { Improve the effectiveness } \\
\text { of intermediaries who } \\
\text { support SMEs in innov- } \\
\text { ation activities }\end{array}$ & $\begin{array}{l}\text { Support start-ups, risk } \\
\text { funding, and networking } \\
\text { in Bio-Tech sector. }\end{array}$ & $\begin{array}{l}\text { Support to hire young } \\
\text { staff for university- } \\
\text { industry link }\end{array}$ & $\begin{array}{l}\text { Traditional R\&D grant } \\
\text { programme on regional } \\
\text { level, focus on input, } \\
\text { and output additionality }\end{array}$ \\
\hline $\begin{array}{l}\text { Intended impact } \\
\text { on behaviour }\end{array}$ & $\begin{array}{l}\text { Firms: cooperation } \\
\text { capabilities, project } \\
\text { management, technol- } \\
\text { ogy, and absorptive } \\
\text { capabilities } \\
\text { Policy: broader network } \\
\text { funding }\end{array}$ & $\begin{array}{l}\text { Improved capabilities to } \\
\text { innovate (firms), } \\
\text { improved capabilities to } \\
\text { support innovation } \\
\text { (intermediaries) }\end{array}$ & $\begin{array}{l}\text { Multi-dimensional, change } \\
\text { of attitude in sector } \\
\text { (risk taking) and } \\
\text { capabilities for network- } \\
\text { ing/clustering }\end{array}$ & $\begin{array}{l}\text { Making staff more capable } \\
\text { of moving between } \\
\text { firms and universities, } \\
\text { organizations to under- } \\
\text { stand benefit and } \\
\text { challenges }\end{array}$ & $\begin{array}{l}\text { Originally no behavioural } \\
\text { dimension tackled in } \\
\text { programme }\end{array}$ \\
\hline $\begin{array}{l}\text { Purpose of } \\
\text { evaluation }\end{array}$ & $\begin{array}{l}\text { Formative and summative, } \\
\text { initially focus on impact } \\
\text { on markets rather than } \\
\text { learning }\end{array}$ & $\begin{array}{l}\text { Mandatory check for ac- } \\
\text { countability and } \\
\text { progress measurement }\end{array}$ & $\begin{array}{l}\text { Summative and formative, } \\
\text { to be used to market } \\
\text { programme and region }\end{array}$ & $\begin{array}{l}\text { Summative, measure } \\
\text { uptake, impact, } \\
\text { cost-effectiveness, } \\
\text { output additionality, } \\
\text { largely for } \\
\text { accountability }\end{array}$ & $\begin{array}{l}\text { Trace BA to further } \\
\text { increase legitimacy of } \\
\text { funding }\end{array}$ \\
\hline $\begin{array}{l}\text { Operationalization } \\
\text { of BA }\end{array}$ & $\begin{array}{l}\text { Components of cooper- } \\
\text { ation capabilities and } \\
\text { changes in action }\end{array}$ & $\begin{array}{l}\text { Interactive definition of } \\
\text { action and change par- } \\
\text { ameters, conceptually } \\
\text { linked to programme }\end{array}$ & $\begin{array}{l}\text { Qualitative measure of risk } \\
\text { taking attitudes and } \\
\text { capabilities to cooper- } \\
\text { ate, quantitative; } \\
\text { numbers on collabor- } \\
\text { ation and foundations }\end{array}$ & $\begin{array}{l}\text { No operationalization of } \\
\text { BA, value of the } \\
\text { concept only became } \\
\text { clear during the evalu- } \\
\text { ation itself. BA was, } \\
\text { then, defined as an ex- } \\
\text { tension to input and } \\
\text { output additionality }\end{array}$ & $\begin{array}{l}\text { Definition of BA in } \\
\text { categories 'more re- } \\
\text { sources for innovation', } \\
\text { 'more ambitious', 'more } \\
\text { cooperation', 'Smarter', } \\
\text { 'Faster' }\end{array}$ \\
\hline $\begin{array}{l}\text { Interaction } \\
\text { evaluator- } \\
\text { policy maker }\end{array}$ & $\begin{array}{l}\text { Evaluators convinced } \\
\text { policy maker to look at } \\
\text { BA change (not only at } \\
\text { final impact) and add } \\
\text { on post project } \\
\text { follow-up } 2 \text { years later. }\end{array}$ & $\begin{array}{l}\text { Evaluators entirely free in } \\
\text { design, BA as concept } \\
\text { not included, but evalu- } \\
\text { ation in fact did look at } \\
\text { BA! }\end{array}$ & $\begin{array}{l}\text { Little interaction, but } \\
\text { policy maker insisted } \\
\text { early on qualitative } \\
\text { aspects and understand- } \\
\text { ing of mechanisms of } \\
\text { change }\end{array}$ & $\begin{array}{l}\text { Programme manager drove } \\
\text { the evaluation, evaluator } \\
\text { was reluctant to extent } \\
\text { evaluation to BA }\end{array}$ & $\begin{array}{l}\text { Programme manager } \\
\text { driving, asking for } \\
\text { robust BA evaluation } \\
\text { after poor input and } \\
\text { output results. No } \\
\text { further interaction in } \\
\text { process }\end{array}$ \\
\hline Methods used & $\begin{array}{l}\text { Context analysis, partici- } \\
\text { pant survey, focus } \\
\text { groups, workshops with } \\
\text { programme owners, } \\
\text { long-term case study } \\
\text { approach (interviews } \\
\text { over a range of years, } \\
\text { beyond project } \\
\text { completion) }\end{array}$ & $\begin{array}{l}\text { Monitoring data and inter- } \\
\text { views, data capture for } \\
\text { clearly defined action } \\
\text { and change parameters, } \\
\text { no measurement of final } \\
\text { impact (as change is } \\
\text { proxy for impact). }\end{array}$ & $\begin{array}{l}\text { Control group approach } \\
\text { (non-funded versus } \\
\text { funded), monitoring } \\
\text { data, survey, and inter- } \\
\text { views (risk taking, } \\
\text { capabilities) }\end{array}$ & $\begin{array}{l}\text { Surveys of all beneficiaries } \\
\text { reinforced by small } \\
\text { number of case studies }\end{array}$ & $\begin{array}{l}\text { Most sophisticated, } \\
\text { multiple control groups, } \\
\text { counter-factual } \\
\text { approach, survey, and } \\
\text { interviews, several pilot } \\
\text { cases }\end{array}$ \\
\hline $\begin{array}{l}\text { Challenge for } \\
\text { the concept }\end{array}$ & $\begin{array}{l}\text { Learning in itself not seen } \\
\text { as hard enough proof } \\
\text { of policy maker that } \\
\text { programme is } \\
\text { successful. }\end{array}$ & $\begin{array}{l}\text { Link between action par- } \\
\text { ameter and programme: } \\
\text { multiple interactions } \\
\text { and permanent revisions } \\
\text { needed }\end{array}$ & $\begin{array}{l}\text { Demonstration of } \\
\text { long-term capability } \\
\text { building and definition } \\
\text { of control group }\end{array}$ & $\begin{array}{l}\text { Limited understanding of } \\
\text { BA during design of } \\
\text { terms of reference, } \\
\text { policy learning too late }\end{array}$ & $\begin{array}{l}\text { Good understanding of } \\
\text { the concept but prag- } \\
\text { matic and simple ma- } \\
\text { nipulation of the } \\
\text { definition }\end{array}$ \\
\hline Limits & $\begin{array}{l}\text { Evaluation limited to co- } \\
\text { operation dimension of } \\
\text { BA, in-depth analysis of } \\
\text { other facets needs more } \\
\text { time and methodological } \\
\text { breadth (sociological, } \\
\text { organizational, psycho- } \\
\text { logical skills, and } \\
\text { methods) }\end{array}$ & $\begin{array}{l}\text { Link of change parameter } \\
\text { with final impact is con- } \\
\text { tested and needs close } \\
\text { monitoring itself, thus } \\
\text { cross-check with final } \\
\text { outcome data needed }\end{array}$ & $\begin{array}{l}\text { Lack of explicit definition } \\
\text { of BA }\end{array}$ & $\begin{array}{l}\text { Programme effects } \\
\text { under-stated because of } \\
\text { lack of conceptualiza- } \\
\text { tion, evaluator not } \\
\text { flexible to adjust to BA } \\
\text { logic during the process }\end{array}$ & $\begin{array}{l}\text { Low process and policy } \\
\text { benefit due to isolation } \\
\text { of evaluator and lack of } \\
\text { recommendation }\end{array}$ \\
\hline $\begin{array}{l}\text { Perceived benefit } \\
\text { of BA } \\
\text { evaluation }\end{array}$ & $\begin{array}{l}\text { Educating policy makers } \\
\text { about impact } \\
\text { mechanisms }\end{array}$ & $\begin{array}{l}\text { Broad and interactive } \\
\text { understanding impact } \\
\text { mechanisms }\end{array}$ & $\begin{array}{l}\text { To market programme } \\
\text { and region }\end{array}$ & Legitimization & Legitimization \\
\hline $\begin{array}{l}\text { Key feature of the } \\
\text { BA evaluation }\end{array}$ & $\begin{array}{l}\text { Dynamic definition of BA } \\
\text { during evaluation and } \\
\text { contested nature of } \mathrm{BA} \\
\text { evaluation }\end{array}$ & $\begin{array}{l}\text { Interactive } \\
\text { operationalization, be- } \\
\text { haviour change as } \\
\text { explicit proxy for } \\
\text { outcome }\end{array}$ & $\begin{array}{l}\text { Elaborated methodology, } \\
\text { pre-defined by policy } \\
\text { maker, longitudinal, } \\
\text { good BA capture }\end{array}$ & $\begin{array}{l}\text { Multiple BA mechanisms } \\
\text { (firms universities, indi- } \\
\text { viduals), not exploited } \\
\text { in evaluation }\end{array}$ & $\begin{array}{l}\text { Most elaborated method- } \\
\text { ology to tackle BA, } \\
\text { good BA capture, but } \\
\text { under-utilization in pol- } \\
\text { itical process }\end{array}$ \\
\hline
\end{tabular}


and counterfactual approaches etc. (Case 5) necessitate advanced methodological skills and conceptual knowledge, which for BA evaluations in innovation policy have not yet diffused and apparently are not easily and automatically translated into policy learning.

\section{Discussion: idiosyncrasies and three types of BA uses in evaluations}

The empirical analysis of the use of the BA concept in evaluation practice has unearthed a set of critical findings that can and must lead to further improvements of both the concept and its operationalization and use. The text analysis has shown that the concept itself is used in very different ways; there is no dominant understanding in evaluation and policy practice of what it means. The problem is not so much the fact that there are different understandings of a concept. The problem is that the concept is often not explicitly stated and defined, and that is defined in ways that are not adequate to the purpose of the evaluations and the intervention logic of the measure that is evaluated. Very often the label is a misnomer, as evaluations do not look at change in behaviour, but simply at the immediate effect as a result of the condition of a programme. There is no persistency analysis and often change is limited to increases in collaboration.

The statistical analysis of the nature of BA evaluations has shown, in general terms, fewer idiosyncrasies than expected. BA is predominantly evaluated together with input and output additionality. The three evaluation topics share a large common ground and their characteristics are somewhat different from the rest of the data. Within this pattern, BA shows the most distinct characteristics out of these three. One area of diversion from other types of additionality is that $\mathrm{BA}$ is related to knowledge generation as much as it is to value generation since it links more closely to scientific and technological impacts. Although there are some minor statistically significant differences, overall, BA evaluations are not dramatically method biased. While qualitative methods are used slightly more often, both qualitative and quantitative methods are used together and separately. Furthermore, perceived quality and usefulness difference between these two method sets are minimal (c.f. Georghiou 2007). Finally, BA evaluations are not perceived to be of higher quality or more useful than other evaluations in general.

The analysis of cases that made use of the concept confirmed, first of all, that the understanding as to what BA constitutes in each case had to be constructed. It is a more or less conscious process of defining what behaviour the intervention seeks to influence and how this is linked to the final goals of the programmes. The construction of this understanding is time consuming as it is complex to understand the building blocks of behaviour and the connections between behaviour and innovation performance. BA, while understood to be a means to an end, can become an end in itself if evaluations are done early in the policy cycle and an increase in performance cannot yet be measured. This is valid as long as the conceptual link between the change in behaviour and the innovation performance is plausible. There is, however, an inherent danger that even if this logic is implemented, the evaluation design does not-or cannot given constraints in evaluation studies (budgets, skills, mutual understanding) - match the actual needs.

As regards the uptake and use of the BA concept in evaluations, our exploratory cases indicate a (simplified) typology. As the case studies demonstrate three possible reasons for and corresponding uses of $\mathrm{BA}$ evaluations can be discerned: (1) behaviour focused, (2) integrated, and (3) instrumental.

First of all, some policy measures have an evolutionary rationale and thus seek to change behaviour of actors as a key objective in itself (behaviour focused approach). Correspondingly, they systematically plan for measuring BA effects and employ the concept as a learning tool. Case 1 to some extent, after a cumbersome learning process of policy makers, would represent such a case. In those cases, we observe that BA is more useful if it is defined clearly in key policy documents and embedded into policy rationale. Similarly, a shared understanding between programme owner and policy maker of the behavioural effects that the policy measure is aimed at results in a dramatic increase of the policy-making value of the concept. Involvement of all possible stakeholders in the process of BA evaluation increases both the product use (i.e. use of the actual report) and process use (i.e. use of the evaluation process) of evaluation (Patton 1998).

Secondly, BA is evaluated in addition and complementary to traditional concepts (output and input additionality, impact, etc.) in an integrated approach. In those cases it is understood that change of behaviour is a pre-condition for other effects to be achieved. An integrated BA approach needs a clear logic model for the intervention in order to understand the meaning of behavioural change and to achieve the final ends of the programme (Case 2, Case 3, to some extent Case 4).

The third possible reason for evaluating BA stems from the need for legitimacy for policy measures. In some cases, we find an instrumental use of the concept (Case 5, to some extent Case 4). There are instances in which the policy makers and evaluators struggle to find evidence for the final programme goals related to input or output additionality. This may be because of time reasons, as especially output additionality and broader economic impact materialize only with a severe time lag. It may also simply be that the programme does not have such effects (i.e. it is unsuccessful). BA then is sometimes introduced ex post, to show impact in terms of learning effects. This is instrumental and questionable in cases in which BA is used to cover up the lack of effects in other dimensions, or to legitimize 
policy ex post. In those cases we find a lack of conceptual clarity for BA which allows manipulation of the result of evaluation. In specific case studies, we observe that such BA evaluations are almost over-designed with extremely and unnecessarily sophisticated methods, while they completely fail to provide any sound recommendations, except for the continuation of the programme, and hence do not provide any policy learning (Case 5).

\section{Conclusion}

The aim of this article is to work towards an improved conceptualization and application of the BA concept as an integral part of sound evaluation in innovation policy. Indeed, the analysis has shown that this is timely. Judging from the widespread use of the BA concept in evaluation, it appears that policy makers and evaluators recognize the need to measure, understand, and interpret change in behaviour as an important effect of interventions which is a necessary - albeit not sufficient - condition for innovation policy measures to work. It seems that many policy makers have realized that without looking at the scope of those effects, their strengths, their pre-conditions, and their linkages to the other types of additionality (input, output) higher order effects (outcome, impacts), we are indeed running the risk of under-evaluation (Georghiou 2007).

However, since the concept of BA has been introduced in evaluations in innovation (and science) policy, it has remained fuzzy and stirred controversy about its specific character, its preconditions, and its usefulness. Our analysis has shown that although the importance of BA is recognized and the concept appears to be applied more often, it is ill-conceived or only used in a limited way. The methods used are not appropriate and the multiple dimensions of behaviour and the cascade effects of changes in behaviour on innovation performance and management more generally are not conceptualized.

Our attempt to systematize the existing approaches to $\mathrm{BA}$ and the subsequent definition of three types of $\mathrm{BA}$ usage are a first step towards a more commonly shared conceptualization. However, a further obstacle for conceptualizing at this stage and for evaluation and policy practice in this context is that despite a consensus in the academic literature on the significance of the concept, there is no such academic unanimity about what exactly BA is and what it means. While some scholars put it at the very heart of the evolutionary/structuralist understanding of innovation policy, others see it as an additional dimension that may fill gaps in understanding policy effects. This is indeed highly problematic for evaluation practice, because as the effects of $\mathrm{BA}$ on innovation dynamics in firms are complex, time consuming, and intertwined with other influences, evaluations must clearly establish the conceptual link between (1) the policy intervention, (2) the behavioural change observed, and (3) the innovation effect and then empirically verify it. In order to do so, the concept still requires a better theoretical foundation to derive a more suitable framework of analysis with a better defined unit of analysis: behaviour and its various components.

Furthermore, the concept needs methodological clarifications. Empirically, BA evaluations do not apply a significantly different set of methods and approaches and even the most sophisticated approaches fail to ask the 'right questions'. However, our conceptual discussion and in-depth analysis of cases has shown that a full analysis of changes over time would need a range of methods (ethnographic, time sensitive and accompanying interviews, etc.), drawing on different disciplines (innovation studies, psychology, organizational sociology). A comprehensive understanding of behavioural change would need a broad mix of methodologies that cannot be applied in all cases. Experimental methodological developments are called for to allow for a simplified yet relevant set of approaches, especially if new disciplines such as organizational sociology with ethnographic means come in.

The case studies have shown that BA is used for very different objectives ranging from legitimization to operational learning. But no matter what the rationale, the complexity of BA asks for a strong interaction and communication between those commissioning the evaluation and the evaluators. For operational learning and sound policy feedback, key concepts as to the link of behaviour changes to innovation must be shared between them and expectations clarified early on. This also means that even if sophisticated methods were applied on the basis of a sound conceptual framework, full benefit of the BA concept still would rely on intensive discussion with all stakeholders involved.

Finally, this article and the study on which it is based are only a beginning. More research is needed for a more practical guide of how behaviour can be operationalized and measured in different contexts. It has to be linked to the theoretical literature, however without prescribing a certain understanding and a fixed set of methods. What is required is some guidance that allows policy makers and evaluators to design adequate evaluations that capture the specific nature of behavioural change and its link to the higher order programme objectives. All too often, it seems, we get stuck in a simplified or even instrumental use of a concept that should be at the heart of innovation policy thinking, as innovation is about changing behaviour.

\section{Acknowledgements}

The study that enabled this article was sponsored by the European Commission, DG Enterprise. We would like to thank the sponsor for the financial and intellectual support. Details of the study can be found at the INNO-Appraisal homepage http://www.proinno-europe. eu/page/inno-appraisal. We also thank all the interviewees 
who participated in the case studies and in our policy-maker survey. We also would like to thank Prof. Luke Georghiou for his valuable comments and insights.

\section{Note}

1. More information about the INNO-Appraisal database including data collection procedure can be found at www.proinno-europe.eu/appraisal

\section{References}

Aho, E. et al. (2006) Creating an Innovative Europe, Report of the Independent Expert Group on R\&D and Innovation Appointed Following the Hampton Court Summit and Chaired by Mr. Esko Aho. EU, Brussels.

Bach, L. and Matt, M. (2002) 'Rationale for Science \& Technology Policy'. In: Georghiou, L., Rigby, J. and Cameron, H. (eds) 'Assessing the Socio-Economic Impacts of the Framework Programme (ASIF)', pp. 93-145. Report to European Commission DG Research.

-. (2005) 'From Economic Foundations to S\&T Policy Tools: a Comparative Analysis of the Dominant Paradigms'. In: Llerena, P. and Matt, M. (eds) Innovation Policy in a Knowledge-Based Economy: Theory and Practice, pp. 17-45. Berlin/Heidelberg: Springer.

Bryant, K. (2001) 'Promoting Innovation: An Overview of the Application of Evolutionary Economics and Systems Approaches to Policy Issues'. In: Foster, J. and Metcalfe, J.S. (eds) Frontiers of Evolutionary Economics: Competition, Self-Organisation, and Innovation Policy, pp. 361-383. Cheltenham: Edward Elgar.

Buisseret, T. J., Cameron, H. M. and Georghiou, L. (1995) 'What Difference Does It Make - Additionality in The Public Support Of R\&D In Large Firms', International Journal of Technology Management, 10: 587-600.

Busom, I. and Fernandez-Ribas, A. (2008) 'The Impact of Firm Participation in R\&D Programmes on R\&D Partnerships', Research Policy, 37: 240-257.

Clarysse, B., Bilsen, V. and Steurs, G. (2006) 'Behavioural Additionality of the R\&D Subsidies Programme of IWTFlanders (Belgium)', In: OECD (ed.) Government $R \& D$ Funding and Company Behaviour: Measuring Behavioural Additionality. pp. 91-114. Paris: OECD.

Clarysse, B., Wright, M. and Mustar, P. (2009) 'Behavioural Additionality of R\&D Subsidies: A Learning Perspective', Research Policy, 38: 1517-1533.

Davenport, S., Grimes, C. and Davies, J. (1998) 'Research Collaboration and Behavioural Additionality: A New Zealand Case Study', Technology Analysis \& Strategic Management, 10: 55-67.

Dodgson, M. et al. (2010) Systems Thinking, Market Failure, and the Development of Innovation Policy: The Case of Australia. Queensland and Cambridge: University of Queensland Economics Discussion Papers \& Centre for Business Research Working Papers 403 \& 397.

Edler, J., Amanatidou, E., Berger, M., Bührer, S., Daimer, S., Dinges, M., Garefi, I., Gök, A. and Schmidmyer, J. (2010) 'INNO-Appraisal: Understanding Evaluation of Innovation Policy in Europe (Final Report)'. Manchester: Report to EC DG Enterprise and Industry.

Edler, J. et al. (2012) 'The Practice of Evaluation in Innovation Policy in Europe', Research Evaluation, doi:10.1093/reseval/ rvs014.
Falk, R. (2007) 'Measuring the Effects of Public Support Schemes on Firms' Innovation Activities: Survey Evidence from Austria', Research Policy, 36: 665-679.

Fier, A., Aschhoff, B. and Löhlein, H. (2006) 'Behavioural Additionality of Public R\&D Funding in Germany'. In: OECD (ed.) Government $R \& D$ Funding and Company Behaviour: Measuring Behavioural Additionality. pp. 127150. Paris: OECD.

Georghiou, L. (1998a) 'Effective Innovation Policy: A New Approach', $R$ \& D Management, 28: 58-58.

(1998b) 'Issues in the Evaluation of Innovation and Technology Policy', Evaluation, 4: 37-51.

- (2002a) 'Impact and Additionality of Innovation Policy', IWT-Studies, 40: 57-65.

_ (2002b) 'Innovation Policy and Sustainable Development: Can Innovation Incentives make a Difference?', IWT-Studies, 40: $57-65$.

(2004) 'Evaluation of Behavioural Additionality. Concept Paper', IWT-Studies, 48: 7-22.

-. (2007) 'What Lies Beneath: Avoiding the Risk of Under-evaluation', Science and Public Policy, 34: 743-752.

Georghiou, L. and Clarysse, B. (2006) 'Introduction and Synthesis'. In: OECD (ed.) Government $R \& D$ Funding and Company Behaviour: Measuring Behavioural Additionality. Paris: OECD Publishing.

Georghiou, L. and Keenan, M. (2006) 'Evaluation of National Foresight Activities: Assessing Rationale, Process and Impact', Technological Forecasting and Social Change, 73: 761-777.

Georghiou, L. and Laredo, P. (2006) 'Evaluation of Publicly Funded Research: Recent Trends and Perspectives'. In: OECD (ed.) OECD Science, Technology and Industry Outlook. Paris: OECD Publishing.

Gok, A. (2010) An Evolutionary Approach to Innovation Policy Evaluation: Behavioural Additionality and Organisational Routines. Manchester: PREST, The University of Manchester.

Gok, A. (2011) Evaluation of Behavioural Additionality of Innovation Policy, Atlanta Conference on Science and Innovation Policy, Atlanta, US.

Hall, B. H. (2002) 'The Assessment: Technology Policy', Oxford Review of Economic Policy, 18: 1-9.

Hall, B. H. and Maffioli, A. (2008) 'Evaluating the Impact of Technology Development Funds in Emerging Economies: Evidence from Latin America', European Journal of Development Research, 20: 172-198.

Hsu, F. M., Horng, D. J. and Hsueh, C. C. (2009) 'The Effect of Government-sponsored R\&D Programmes on Additionality in Recipient Firms in Taiwan', Technovation, 29: pp. 204-217.

Hsu, F. M. and Hsueh, C. C. (2009) 'Measuring Relative efFiciency of Government-sponsored R\&D Projects: A Three-stage Approach', Evaluation and Program Planning, 32: $178-186$.

Hyvarinen, J. and Rautiainen, A. M. (2007) 'Measuring Additionally and Systemic Impacts of Public Research and Development Funding - The Case of TEKES, Finland', Research Evaluation, 16: 205-215.

Larosse, J. (2004) 'Conceptual and Empirical Challenges of Evaluating the Effectiveness of Innovation Policies with 'Behavioural Additionality' (The Case of IWT R\&D Subsidies)', IWT-Studies, 48: 57-69.

Licht, G. (2003) The Role of Additionality in Evaluation of Public R\&D Programmes, 11th TAFTIE Seminar on Additionality, Vienna.

Lipsey, R. G. (2002) 'Some Implications of Endogenous Technological Change for Technology Policies in Developing Countries', Economics of Innovation and New Technology, 11: $321-351$. 
Lipsey, R. G. and Carlaw, K. (1998a) A Structuralist Assesment of Technology Policies: Taking Schumpeter Seriously on Policy. Ottawa: Industry Canada.

- (1998b) 'Technology Policies in Neo-Classical and Structuralist-Evolutionary Models', OECD Science Technology and Industry Review, 22: 30-73.

- (2002) The Conceptual Basis of Technology Policy, Department of Economics Discussion Papers, Simon Fraser University Vancouver.

Lipsey, R. G., Carlaw, K. I. and Bekar, C. T. (2005) Economic Transformations: General Purpose Technologies and Long Term Economic Growth. New York: Oxford University Press.

Luukkonen, T. (2000) 'Additionality of EU framework programmes', Research Policy, 29: 711-724.

Malik, K., Georghiou, L. and Cameron, H. (2006) 'Behavioural Additionality of the UK Smart and Link Schemes'. In: OECD (ed.) Government $R \& D$ Funding and Company Behaviour: Measuring Behavioural Additionality. Paris: OECD.

Marianne, B., Nils Henrik, S., Heidi Wiig, A. and Per, M. K. (2001) Technopolis RCN Evaluation - User Oriented R\&D in the Research Council of Norway, The STEP Group, Studies in technology, innovation and economic policy. no: 200108.

Metcalfe, J. S. and Georghiou, L. (1998) 'Equilibrium and Evolutionary Foundations of Technology Policy', OECD Science Technology and Industry Review, 22: 75-100.

Nelson, R. R. (1991) 'Why Do Firms Differ, and How Does It Matter?', Strategic Management Journal, 12: 61-74.
(2005) Technology, Institutions and Economic Growth. Cambridge, Massachusetts: Harvard University Press. . (2009) 'Routines as Technologies and as Organizational Capabilities'. In: Becker, M. C. and Lazaric, N. (eds) Organizational Routines: Advancing Empirical Research. Cheltenham and Northampton: Edward Elgar.

OECD (ed.) (2006) Government R\&D Funding and Company Behaviour: Measuring Behavioural Additionality. Paris: OECD Publishing.

OECD and EUROSTAT. (2006) OECD Proposed Guidelines for Collecting and Interpreting Technological Innovation Data: Oslo Manual, 3rd edn. Paris: OECD.

Patton, M. Q. (1998) 'Discovering Process Use', Evaluation, 4: 225-233.

Schwerin, J. and Werker, C. (2006) 'Innovation and the Learning Policy Maker - An Evolutionary Approach Based on Historical Experience'. In: Dopfer, K. (ed.) Economics, Evolution And The State: The Governance of Complexity. Cheltenham: Edward Elgar.

Smith, K. (2000) 'Innovation as a Systemic Phenomenon: Rethinking the Role of Policy', Enterprise and Innovation Management Studies, 1: 73-102.

Steurs, G. et al. (2006) 'A Look into the Black Box: What Difference do IWT R\&D Grants Make for their Clients?' IWT-Studies, 93: 1-93. 